\title{
Synthesis and characterization of electroless $\mathrm{Ni}-\mathrm{P}$ coated graphite particles
}

\author{
M ANANTH KUMAR*, RAMESH CHANDRA AGARWALA and VIJAYA AGARWALA \\ Metallurgical and Materials Engineering Department, Indian Institute of Technology Roorkee, Roorkee 247 667, India
}

MS received 23 December 2007; revised 25 April 2008

\begin{abstract}
Electroless alkaline bath is used to coat $\mathrm{Ni}-\mathrm{P}$ graphite particles of average size, $150 \mu \mathrm{m}$. Amorphous nickel and graphite phases are observed in X-ray diffraction of the coated particles. The crystallite size from diffraction peaks is found to be $9.56 \mathrm{~nm}$. The microstructural studies are carried out with field emission scanning electron microscope (SEM) on the uncoated and coated graphite particles. Uncoated particles showed irregular and fractured surfaces while the surface of coated particles revealed the presence of $\mathrm{Ni}-\mathrm{P}$ globules. Sizes of Ni-P globules are observed to be in the range $175-250 \mathrm{~nm}$. The presence of $\mathrm{Ni}$ and $\mathrm{P}$ are confirmed by the energy dispersive spectrometer results. The effect of coating bath composition is studied and an increasing trend in deposition is observed up to $50 \mathrm{gl}^{-1}$ of stabilizer as well as up to $20 \mathrm{gl}^{-1}$ of the reducing agent, however, the trend reverses afterwards. The phenomena of nucleation and growth of the Ni-P layer over the graphite surface have been demonstrated through SEM studies and a model has been proposed to demonstrate the growth mechanism of Ni-P globules.
\end{abstract}

Keywords. Graphite; electroless deposition; Ni-P globules; nucleation; growth.

\section{Introduction}

Graphite particles are one of the resourceful engineering materials which have taken indispensable position in the field of metal matrix composites (MMCs). The interfacial reaction and wettability of these particles with the metal matrix plays a key role in processing as well as in the performance of MMCs. These problems could be tackled well enough by applying metallic coatings over the graphite particles. The metallic coating on the graphite particles improves the wettability and several other metallurgical characteristics of the MMCs (Abraham et al 1992; Rams et al 2007). Amongst the wide range of metallic coating processes, electroless (EL) process stands unique for the reason of direct metallization on any material with much ease and can be performed with simple experimental setup (Agarwala 1987). EL metallic coating on graphite powder containing pores with copper and followed by nickel, was reported in the midst of nineties (Caturla et al 1995). Sharma et al (2002) developed in situ EL nickel composite coatings and observed an increase in the tensile strength of carbon fibre. The bath stability as well as the deposition rate of nickel on graphite fibres by EL coating along with the chemical composition of the bath was also reported (Shi et al 1999). It was revealed that catalytic graphitization of carbon fibres is possible through EL nickel coating (Tzeng 2006). Improvement in the wear properties of

*Author for correspondence (clickananth@gmail.com) aluminium matrix composites reinforced with EL nickel coated graphite was reported by Chu and Lin (2000). Recently, Veera Babu et al (2007) and Palaniappa et al (2007) have studied Ni-P coating of graphite particles using acidic EL bath with preheated graphite particles. Though different EL coatings have been studied with carbon and graphite fibres, the EL Ni-P coatings are not explored with micron sized graphite particles using alkaline bath. In this investigation, micron sized graphite particles are coated with Ni-P by alkaline EL bath process. EL Ni-P coated graphite particles are characterized using various techniques. The graphite particles before and after coating are characterized for the phase analysis by X-ray diffraction (XRD) and morphological studies with field emission scanning electron microscope (SEM). Energy dispersive spectrometer studies are also carried out for determining the elemental contents of the uncoated and Ni-P coated graphite particles. The effect of deposition on concentration of stabilizer and concentration of reducing agent is investigated. An attempt is made to assess the nucleation and growth mechanism of Ni-P globules over the graphite surface.

\section{Experimental}

\subsection{Substrate preparation}

Graphite particles used in this process was procured from Amrut Industrial Products, Mumbai, India (size, $\sim 150 \mu \mathrm{m}$ ). 
Weighed quantity of graphite particles was used to account for the bath loading factor which was kept at $25 \%$ as recommended by Agarwala (1987). Bath loading factor was defined as the ratio of surface area of the substrate to the volume of coating bath. EL coating process being a chemical reduction process, surface preparation of the substrate material is mandatory. To carry out surface pretreatment, the weighed graphite particles were packed in a bag of filter paper. Initially the graphite particles were degreased by dipping the bag in acetone to ensure a good adhesion of the EL coatings. Then the particles were sensitized and activated by dipping in $0 \cdot 1 \%$ stannous chloride solution for $2 \mathrm{~min}$ and dipping in $0.01 \%$ palladium chloride solution for $2 \mathrm{~min}$, respectively and dried using hot air drier.

\subsection{Electroless bath composition and operating conditions}

Alkaline EL bath was used to produce Ni-P coated graphite particles. The experimental set up used for the coating process was similar to that of Agarwala (1987), where the temperature of the bath can be controlled to an accuracy of $\pm 0 \cdot 5^{\circ} \mathrm{C}$. The bath composition for coating process was: nickel sulphate, $30 \mathrm{gl}^{-1}$; sodium hypophosphite, $16 \mathrm{gl}^{-1}$; sodium citrate, $80 \mathrm{gl}^{-1}$ and ammonium chloride, $50 \mathrm{gl}^{-1}$. The operating temperature and $\mathrm{pH}$ chosen for EL coating of graphite particles were maintained at $90 \pm 2^{\circ} \mathrm{C}$ and $9 \pm 0 \cdot 25$, respectively. The $\mathrm{pH}$ of the bath was checked frequently and maintained by adding ammonia solution. Two grams of pretreated graphite particles was taken for each trial and coated in the EL bath for ten min. The EL coating bath solution was stirred manually to keep the graphite particles in suspension to ensure complete coating. The concentration of nickel salt, concentration of sodium citrate, amount of graphite particles and time of coating were kept constant throughout the experiments. To study the effect of concentration of stabilizer and reducing agent on deposition, experiments were repeated by varying one of these parameters while keeping the other parameters constant. The variation in deposition was quantified by weighing the sample before and after the coating process. Once the coating was done for the required time, the coated graphite particles were filtered, dried, weighed and then subjected to characterization.

\subsection{Characterization studies}

The phase analysis of the uncoated and Ni-P coated graphite particles was carried out with the help of X-ray diffractometer equipped with scintillation counter and filtered $\mathrm{CuK}_{\alpha}(\lambda=1.54056 \AA)$ radiation (Bruker AXS D8, Germany). The $I-\theta$ diffraction patterns were obtained for $2 \theta$ angles from $25^{\circ}$ to $90^{\circ}$. Diffraction peaks of uncoated as well as Ni-P coated graphite particles were identified using
JCPDS files 23-0064 and 4-0850, respectively. The EDS analysis as well as the morphology of uncoated and Ni-P coated graphite particles were observed with SEM (FEI QUANTA 200F, USA) equipped with EDS (EDAX, USA) facility.

\section{Results and discussion}

The reduction of nickel ion onto the catalysed graphite particles could be inferred during the coating process by the evolution of hydrogen gas from the substrate. This could be well noticed by the effervescence of gas from the suspended graphite particles in the EL bath solution.

\subsection{XRD characterization}

The XRD pattern of the uncoated and Ni-P coated graphite particles obtained is shown in figure 1. The diffraction pattern of uncoated graphite particles depicts peaks of graphite which is the substrate for developing the coatings. Sharma et al (2002) also reported identical XRD pattern for the uncoated carbon fibre. In the diffraction pattern of $\mathrm{Ni}-\mathrm{P}$ coated graphite particles peaks corresponding to graphite and nickel phases are present. The presence of nickel could be affirmed by the peak at $\approx 44.5^{\circ}$ which is shown as enlarged section in figure 1 . The broadening of peak in XRD signifies that the deposit is of amorphous nature. The phase analysis findings of Rams et al (2007) of nickel coated carbon fibres and the results of phase analysis carried out by Shi et al (1999) on EL nickel coated graphite fibres corroborate with the present study. Sharma et al (2002) also proclaimed that Ni-P coated carbon fibre exhibits analogous type of XRD patterns prior to its heat treatment. It could be stated that the broadening of peak at $\approx 44.5^{\circ}$ confirm the feasibility of developing the EL Ni-P coatings on graphite particles.

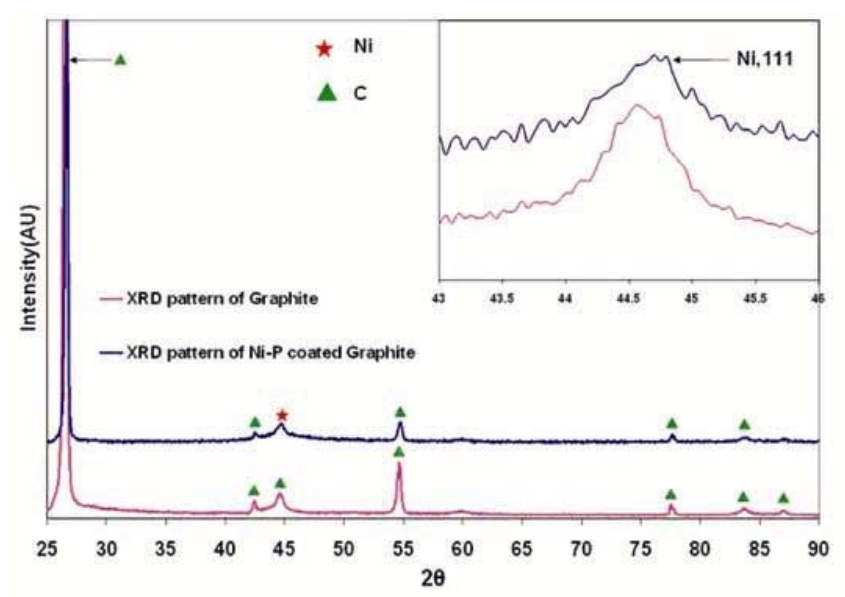

Figure 1. XRD pattern showing peaks of uncoated and Ni-P coated graphite particles. 

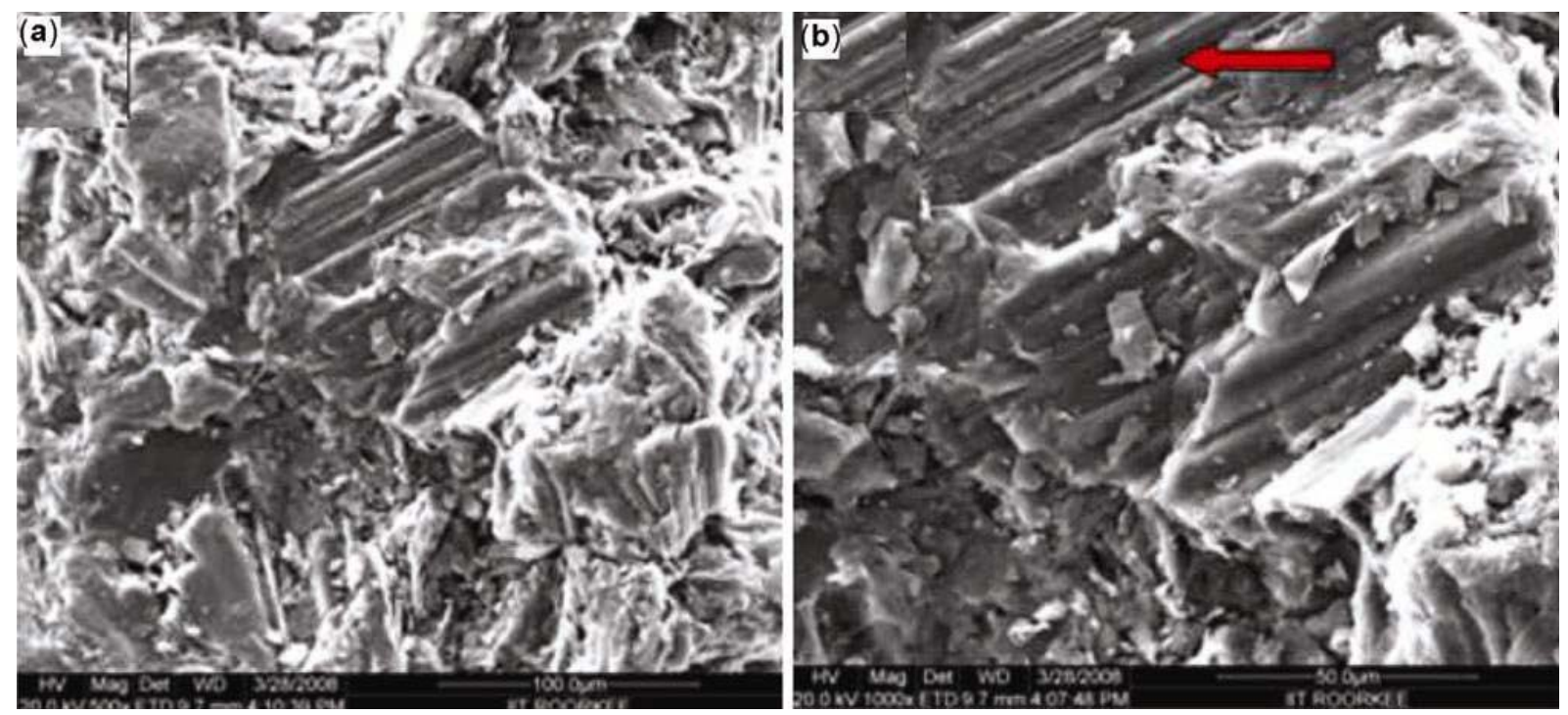

Figure 2. FESEM micrographs at different magnifications depicting a. fractured and irregular surfaces of graphite particle and $\mathbf{b}$. showing the V-grooves marked by arrow.

The crystallite size $(D)$ of Ni-P coatings is deduced from the diffraction peak using Scherrer's formula

$$
D=\frac{K \lambda}{(F W) \cos \theta},
$$

where $K$ is the shape factor of the average crystallite (0.94), $\lambda$ the X-ray wavelength $(0 \cdot 154056 \mathrm{~nm}$ for $\mathrm{CuK} \alpha)$, FW the full width at half maximum of the diffraction peak, and $\theta$ the diffraction peak angle. From (1), the crystallite size is inversely proportional to the $\mathrm{FW}$ of the diffraction peak. Broader peak in X-ray diffraction patterns signifies smaller crystallite size. The crystallite size calculated using Scherrer's formula for the Ni-P coating is $9.56 \mathrm{~nm}$. The crystallite sizes reported earlier by others were also in agreement with the present results (Sampath Kumar and Kesavan Nair 1996; Veera Babu et al 2007).

\subsection{SEM characterization}

The SEM micrographs of uncoated graphite particles at different magnifications exhibiting fractured and irregular surfaces are illustrated in figure $2(a, b)$. V-grooves are also observed on the surface of graphite particles (shown by arrow in figure $2 b$ ). The surface of graphite particles are fractured and appear irregular, which might have occurred during powdering process. The Ni-P coated graphite particles reveal typical Ni-P globules over the catalytic graphite surface as shown in figure $3(a, b)$. It can also be observed that the Ni-P coating penetrates into the fractured V-groove surface of the graphite particles (represented by an arrow in figure $3 \mathrm{~b}$ ). Clustering of globular structure of Ni-P was also reported by Rams et al (2007). The reports of other researchers also reveal identical globular structure of $\mathrm{Ni}-\mathrm{P}$ coatings over the catalyzed carbonaceous surface (Caturla et al 1995; Shi et al 1999; Sharma et al 2002; Veera Babu et al 2007; Palaniappa et al 2007). The micrographs shown in figure $4(a, b)$ reveal that initially the globules of Ni-P nucleate vertically and then flatten horizontally and ensures a complete coating all over the catalytic graphite surface. Subsequent layers of Ni-P coating develops over the initial seed layer of $\mathrm{Ni}-\mathrm{P}$ (figure 4b). The process of uniform growth of the EL coating repeats further to form an adherent layer over the catalytic graphite surface. From figure 4a the size of $\mathrm{Ni}-\mathrm{P}$ globules could be approximated between 175 and $250 \mathrm{~nm}$ which is one of the exceptional features of the EL $\mathrm{Ni}-\mathrm{P}$ coatings. The sizes of Ni-P globules reported by Wang et al (2000) were also in the specified range.

\subsection{EDS characterization}

The EDS analysis is carried out for the uncoated and Ni$\mathrm{P}$ coated graphite particles (figure 5). The EDS spectrum of uncoated particles reveals the presence of oxygen along with graphite (figure 5a). The mechanically powdered graphite will have the presence of oxygen because of enhanced reactivity on the surface which has been previously reported (Harker et al 1971; Ong and Yang 2000). The weight percent of nickel, phosphorous and carbon measured from EDS spectrum is uniform throughout the $\mathrm{Ni}-\mathrm{P}$ coated graphite particles. A similar type of EDS spectrum of Ni-P coated graphite showing the presence of same elements was also reported earlier by Palaniappa et al (2007). The weight percent of phosphorous was between 5 and $7 \%$ when EL coating is carried out at pH 9. Similar results were also reported by Rams et al (2007). The EDS studies show the presence of $\mathrm{Ni}$ and $\mathrm{P}$, which is also seen as globules in the SEM micrographs (figures 3 

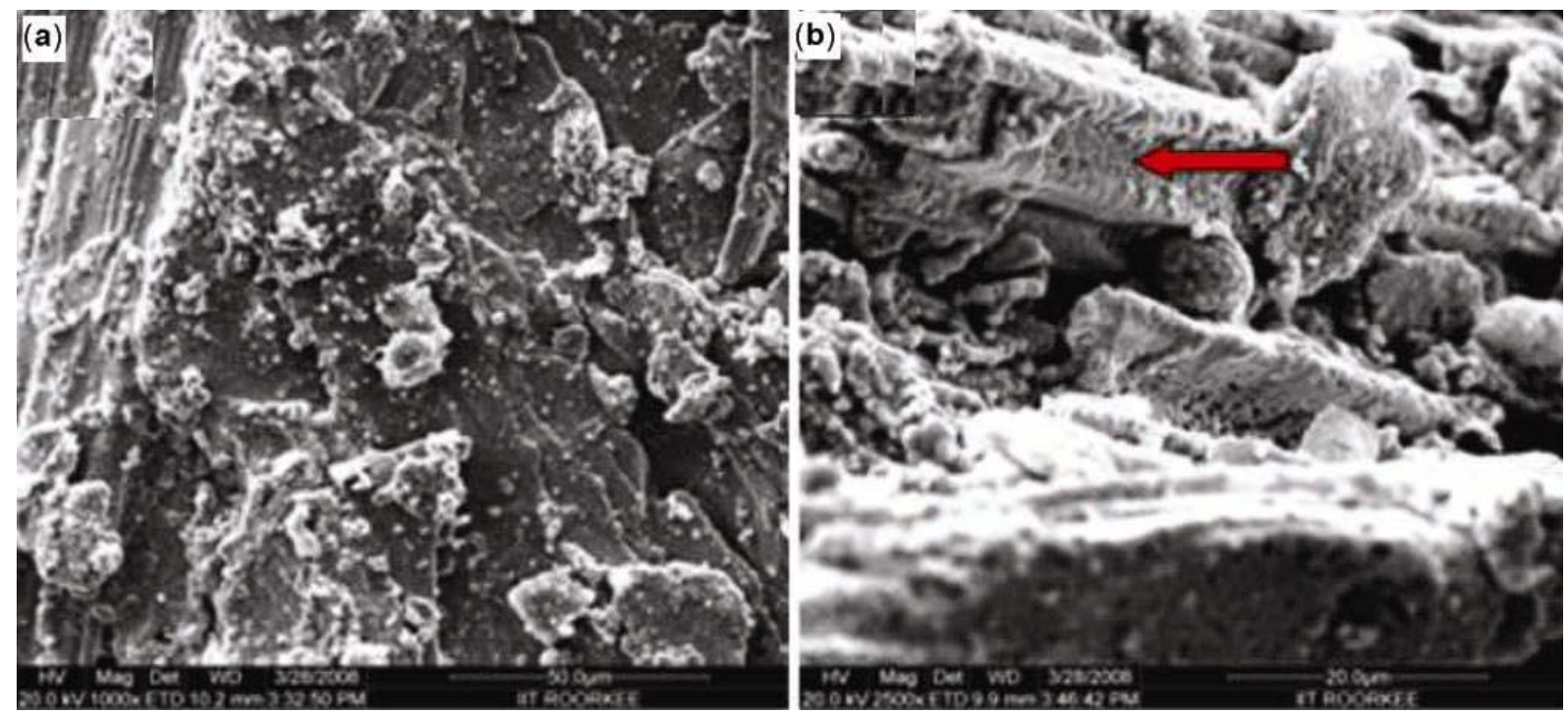

Figure 3. FESEM micrographs showing a. Ni-P coated graphite particles and $\mathbf{b}$. deposition of Ni-P globules on V-groove indicated by arrow.
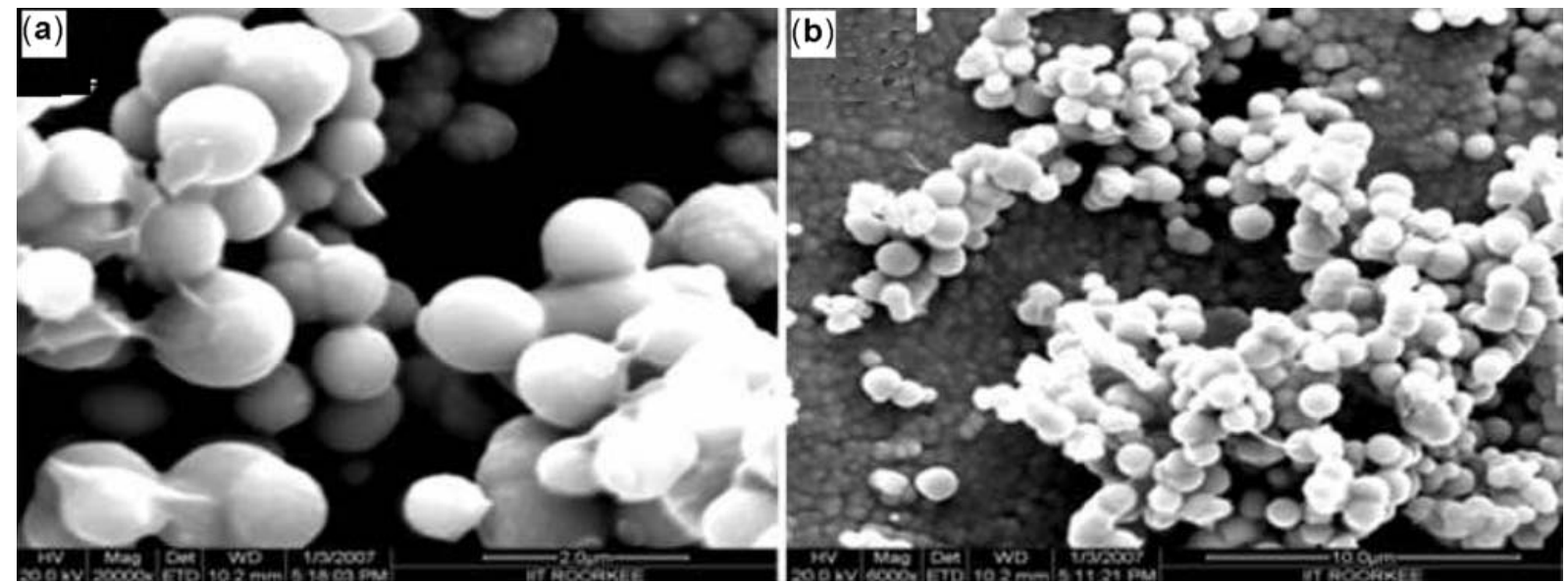

Figure 4. SEM micrographs showing a. Ni-P globules growing vertically and $\mathbf{b}$. vertical growth of Ni-P globules on seed layer over graphite particles.

and 4). By correlating the EDS results with the SEM micrograph, the presence of Ni-P particles is confirmed in EL coating.

\subsection{Effect of process variables on EL Ni-P coatings}

3.4a Effect of stabilizer concentration: The effect of stabilizer concentration on the deposition of Ni-P by EL coating is studied in the range from $35 \mathrm{gl}^{-1}$ to $55 \mathrm{gl}^{-1}$. Ammonium chloride is used as the stabilizer in this study. The purpose of stabilizer is to ensure that deposition occurs at a specific rate on the substrate and to avoid decomposition mainly by orthophosphite colloidal particles, which are generated inside the bath. The variation in the deposition is measured by weight gain method and its variation with the concentration of ammonium chloride is shown in figure 6. The increase in deposition with the concentration of the stabilizer is noticed up to a maximum of $50 \mathrm{gl}^{-1}$ of the stabilizer. Beyond that level there is a decline in the deposition, which may be due to the inhibiting nature of stabilizer. This is because as the concentration of stabilizers increases, it increases the deposition, which is the primary function of stabilizer. At higher concentration of the stabilizer, the colloidal particles generated in the bath absorb the stabilizers, thus avoiding decomposition at the expense of deposition. The stability of bath has been prolonged at the expense of the deposition. The identical nature of decline in deposition for different stabilizers has been reported by Cheong et al (2004).

3.4b Effect of reducing agent concentration: The variation in deposition is observed by varying the amount of 

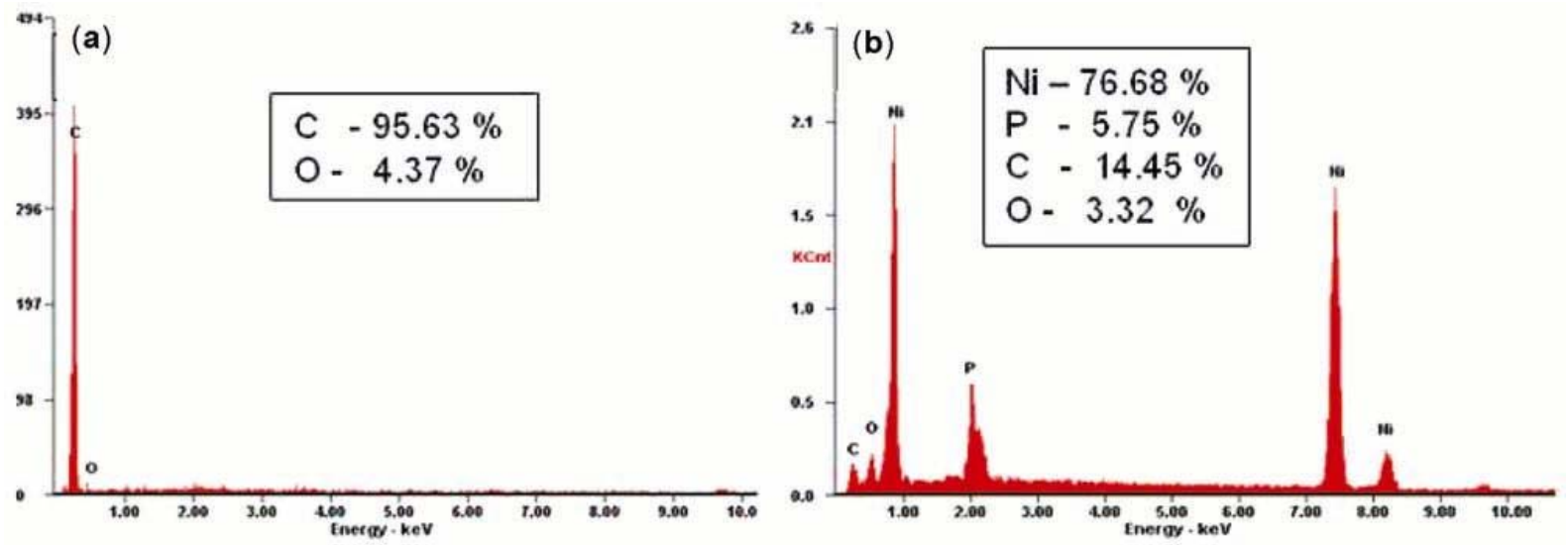

Figure 5. EDS spectrum a. graphite particles and b. Ni-P coated graphite particles.

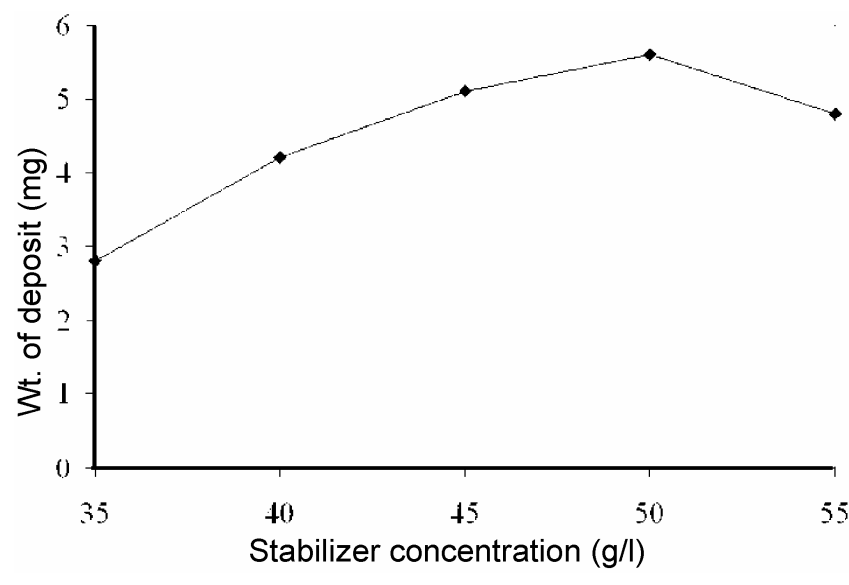

Figure 6. Variation of $\mathrm{Ni}-\mathrm{P}$ deposition with concentration of stabilizer.

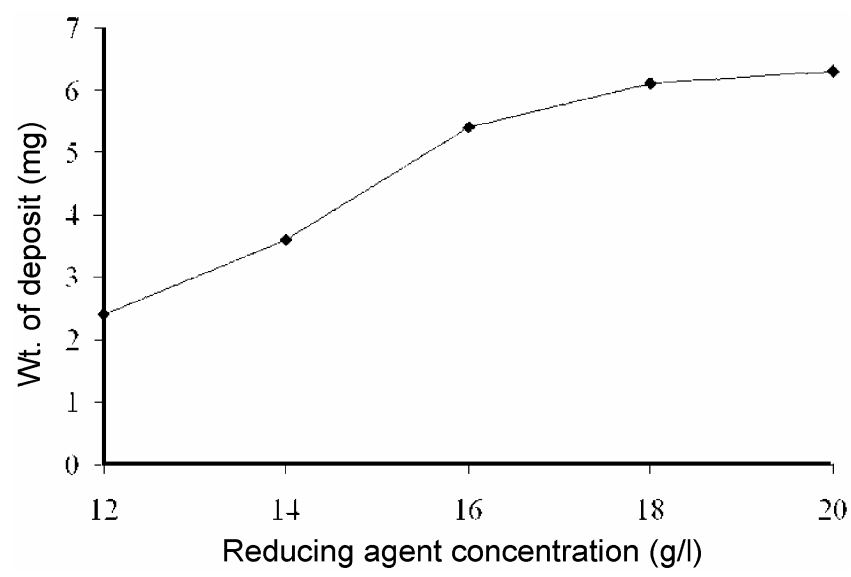

Figure 7. Variation of Ni-P deposition with concentration of reducing agent.

reducing agent, sodium hypophosphite, from $12 \mathrm{gl}^{-1}$ to $20 \mathrm{gl}^{-1}$. It is noted that the amount of reducing agent in the coating bath has significant effect on deposition. The variation in deposition with amount of sodium hypophosphite is shown in figure 7 . The function of reducing agent is to supply electrons for the reduction of nickel ions. The deposition increases initially with the concentration of reducing agent up to $18 \mathrm{gl}^{-1}$. However, at $20 \mathrm{gl}^{-1}$ of sodium hypophosphite deposition of Ni-P saturates and further increase in the concentration of sodium hypophosphite results in instability of the coating bath. Initial increase in Ni-P deposition with the amount of reducing agent may be due to the superfluous availability of free electrons for the reduction process. The tendency of saturation in deposition occurs while increasing reducing agent, because the amount of nickel salt available for reduction remains constant. The instability of the bath happens because of the limited stabilizer content to combat the generation of orthophosphite. The same type of results has been established in Ni-B coating by Anita Srivastava et al (1992).

\subsection{Proposed nucleation and growth mechanism of $\mathrm{Ni}-\mathrm{P}$ on graphite particles}

The proposed model for the nucleation and growth of $\mathrm{Ni}-$ $\mathrm{P}$ globules at the surface area of the graphite particles is shown schematically in figure $8(a-d)$. From the SEM micrographs (figure 2), the fractured graphite particles resemble as ' $\mathrm{V}$ ' grooves all over its surface. The resemblance of this V-groove is shown in figure $2 b$. During pretreatment process of graphite particles, stannous ions will be deposited first which are then replaced by palladium ions. Subsequently, the palladium ions will act as catalyst for the nucleation of Ni-P coating over the graphite particles (figure 3). Once the initial layer of $\mathrm{Ni}-$ $\mathrm{P}$ globules are formed, it themselves will act as catalyst for further coating process. The nucleation and growth of $\mathrm{Ni}-\mathrm{P}$ globules filling the $\mathrm{V}$-groove is indicated by an arrow in figure $3 \mathrm{~b}$. The subsequent layer of $\mathrm{Ni}-\mathrm{P}$ coating forming one over other on the graphite surface is indicated in figure $4 b$. 


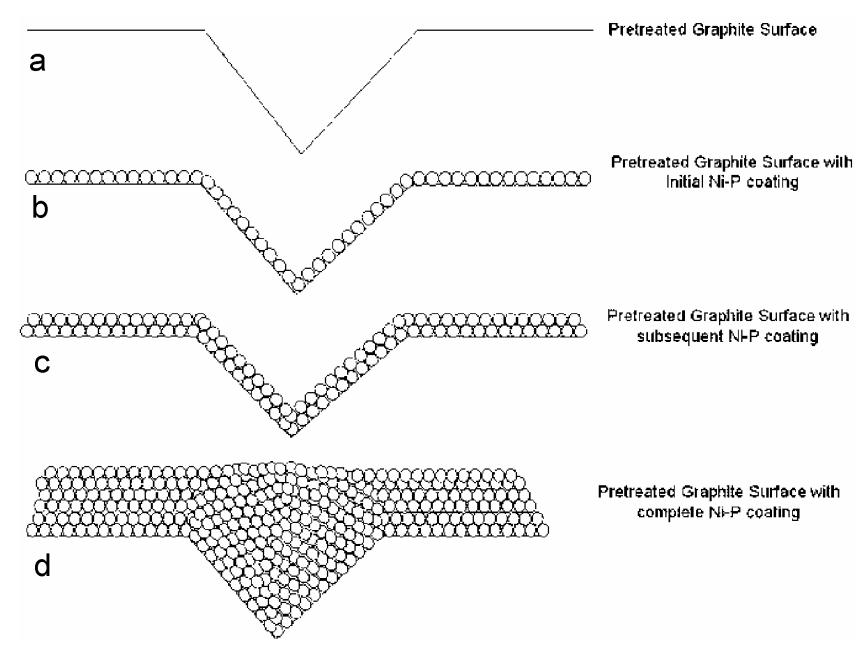

Figure 8(a-d). Schematic illustration of nucleation and growth of Ni-P globules on graphite surface.

\section{Conclusions}

(I) Ni-P coating on graphite particles is successfully done using alkaline EL bath.

(II) The crystallite size of the $\mathrm{Ni}-\mathrm{P}$ coating is found to be $9.56 \mathrm{~nm}$.

(III) EL Ni-P coating is found to be uniform over the complete surface including the intricate gaps and surface defects in the graphite particles.

(IV) The size of Ni-P globules coated on the graphite particles are observed to be in the range of 175-250 $\mathrm{nm}$.

(V) The EDS studies in correlation with SEM micrograph confirms the presence of nickel and phosphorous on the coated graphite particles.

(VI) The saturation limit of stabilizer is found to be $50 \mathrm{gl}^{-1}$, beyond which it inhibits the deposition of Ni-P coatings.

(VII) Deposition of Ni-P improves up to $20 \mathrm{gl}^{-1}$ of reducing agent, above which decomposition of coating bath is observed.
(VIII) EL Ni-P coatings seem to nucleate vertically in globule form and then flatten to cover the entire catalyzed graphite particles.

\section{Acknowledgement}

The authors acknowledge MHRD, New Delhi, for funding the research work.

\section{References}

Abraham S, Pai B C and Satyanarayana K G 1992 J. Mater. Sci. 273479

Agarwala R C 1987 Structural studies and crystallization behaviour of electroless $\mathrm{Ni}-\mathrm{P}$ films, Ph.D. Thesis, University of Roorkee, Roorkee

Caturla F, Molina F, Molina-Sabio M and Rodriguez-Reinoso F 1995 J. Electrochem. Soc. 1424084

Cheong W J, Luan Ben L and Shoesmith David W 2004 Appl. Surf. Sci. 229282

Chu Hsiao Yeh and Lin Jen Fin 2000 Wear 239126

Harker H, Horsley J B and Robson D 1971 Carbon 91

Ong T S and Yang H 2000 Carbon 382077

Palaniappa M, Veera Babu G and Balasubramanian K 2007 Mater. Sci. \& Engg. A471 165

Rams J, Uren̈a A, Escalera M D and Sanchez M 2007 Composites Part A 38566

Sampath Kumar P and Kesavan Nair P 1996 J. Mater. Process. Technol. 56511

Sharma S B, Agarwala R C, Agarwala V and Satyanarayana K G 2002 J. Mater. Sci. 375247

Shi Ziyuan, Wang Xuezhi and Ding Zhimin 1999 Appl. Surf. Sci. 140106

Srivastava Anita, Mohan Sunil, Agarwala Vijaya and Agarwala Ramesh C 1992 Z. Metallkunde 83251

Tzeng Shinn-Shyong 2006 Carbon 441986

Veera Babu G, Palaniappa M, Jayalakshmi M and Balasubramanian K 2007 J. Solid State Electrochem. 111705

Wang C Y, Zhou Y, Zhu Y R, Hu Y and Chen Z Y 2000 Mater. Sci. \& Engg. B77 135 